\title{
Vietnamese Rainbow Films - A Young and Shining flower of Southeast Asian LGBT Culture in a Time of Globalization
}

\author{
Tien Quyet Ly \\ Head of Department of Southeast Asian Studies at the HCMC \\ Ho Chi Minh City Open University, Vietnam
}

\begin{abstract}
In recent years, we have witnessed the appearance of a series of Vietnamese LGBT films on the world screen. These films featured different aspects of same-sex sexuality and relationships in Vietnam, one of the last communist countries in the world. The heroes and heroines in these films, despite their differences from one another, have touched the heart of the Vietnamese, earning their sympathy, creating a positive impact and contributing to the birth of a young and fascinating LGBT culture in the country.

After long decades of unrecognition, the portraits of the Vietnamese LGBT community displayed in these films is a positive one, treated humanely and respectfully. The time to come for the gays and lesbians to be seen as normal as everyone else, not as people suffering a kind of behavioral disease which is mocked and discriminated against by society. Rich in colors, the fresh new Vietnamese rainbow culture has quickly integrated in the regional and international LGBT movement and acted as a motor which stimulates other cultural LGBT activities in strictly conventional and authoritarian Southeast Asian countries. The globalization of culture with its different facets together with the high tech revolution of media have exerted a great influence on the Vietnamese LGBT cultural movement and driven important changes in Vietnamese social perspectives regarding the role and the LGBT status in the country.

The paper examines the background in which the Vietnamese LGBT culture was born and develops; its challenges and difficulties as well as its common features with that of the neighbors and its own particularity. The paper also studies its identity, positive role and contribution to the progress of the right movement for the equality and happiness of the LGBT in Southeast Asia.
\end{abstract}

Keywords: Vietnam, LGBT, film, rainbow, culture 